\title{
Characterization of Species of Diaporthe from Wood Cankers of Grape in Eastern North American Vineyards
}

Kendra Baumgartner and Phillip T. Fujiyoshi, Crops Pathology and Genetics Research Unit, United States Department of Agriculture-Agricultural Research Service (USDA-ARS), Davis, CA 95616; Renaud Travadon, Department of Plant Pathology, University of California, Davis; Lisa A. Castlebury, Systematic Mycology and Microbiology Laboratory, USDA-ARS, Beltsville, MD 20705; Wayne F. Wilcox, Department of Plant Pathology and Plant Microbe Biology, Cornell University, Geneva, NY 14853; and Philippe E. Rolshausen, Department of Plant Pathology and Microbiology, University of California, Riverside 92521

\begin{abstract}
Baumgartner, K., Fujiyoshi, P. T., Travadon, R., Castlebury, L. A., Wilcox, W. F., and Rolshausen, P. E. 2013. Characterization of species of Diaporthe from wood cankers of grape in eastern North American vineyards. Plant Dis. 97:912-920.

In eastern North America, Phomopsis cane and leaf spot, caused by Phomopsis viticola, is a foliar disease of grape but, in the Mediterranean climate of western North America, $P$. viticola is primarily associated with wood cankers, along with other Diaporthe spp. To determine the identity of wood-infecting Diaporthe spp. in eastern North America, 65 isolates were cultured from 190 wood-canker samples from 23 vineyards with a history of Phomopsis cane and leaf spot. Identification of 29 representative isolates was based initially on morphology, followed by phylogenetic analyses of DNA sequences of the ribosomal DNA internal transcribed spacer region, elongation factor subunit 1- $\alpha$, and actin in comparison with those of type specimens. Three species

were identified: P. viticola, P. fukushii, and Diaporthe eres. Inoculations onto woody stems of potted Vitis labruscana 'Concord' and $V$. vinifera 'Chardonnay' showed that $D$. eres and $P$. fukushii were pathogenic (mean lesion lengths of 7.4 and $7.1 \mathrm{~mm}$, respectively, compared with $3.5 \mathrm{~mm}$ for noninoculated controls) but significantly less so than wood-canker and leaf-spot isolates of $P$. viticola $(13.5$ $\mathrm{mm})$. All three species infected pruning wounds of Concord and Chardonnay in the field. Our finding of pathogenic, wood-infecting $\mathrm{Di}$ aporthe spp. in all 23 vineyards suggests a frequent co-occurrence of the foliar symptoms of Phomopsis cane and leaf spot and wood cankers, although the latter are not always due to $P$. viticola.
\end{abstract}

Phomopsis cane and leaf spot is common in eastern North American vineyards $(24,32)$, which primarily produce juice and preserve grape cultivars (e.g., 'Concord'). Leaves develop tiny, necrotic spots with rounded margins, surrounded by a chlorotic halo. Infections of green stems and the rachis result in dark brown and necrotic lesions. The causal fungus Phomopsis viticola (Sacc.) Sacc. (family Diaporthaceae, order Diaporthales) overwinters as mycelium or pycnidia (perithecia have not been observed; 38) on dormant canes colonized as green shoots during the preceding growing season (47). Conidia are dispersed with rain. Under optimal temperature and wetness conditions, which are common at the start of the growing season, conidia germinate and penetrate the rapidly growing shoots (9). Heavily spotted leaves and rachises often abscise or break. Fruit is susceptible at all stages of development, and fruit rot can diminish yields significantly $(8,27)$. Infected shoots that are retained as spurs or canes during dormant-season pruning give rise to weak shoots the following growing season (47).

In California and other grape-growing regions with Mediterranean climates, the growing season tends to be much drier than in

Corresponding author: K. Baumgartner,

E-mail: kbaumgartner@ucdavis.edu

Research was funded by grant number 2008-51100-19334 to K. Baumgartner and P. E. Rolshausen from the USDA, National Institute of Food and Agriculture. USDA is an equal opportunity provider and employer.

* The $e$-Xtra logo stands for "electronic extra" and indicates that one supplementary figure and one supplementary table are available online.

Accepted for publication 18 January 2013.

http://dx.doi.org/10.1094/PDIS-04-12-0357-RE

This article is in the public domain and not copyrightable. It may be freely reprinted with customary crediting of the source. The American Phytopathological Society, 2013. eastern North American vineyards and, thus, is rarely conducive to infection of green tissues. In these regions, $P$. viticola is better known as a wood-canker pathogen $(42,43)$. A wood canker is revealed by cutting a cross-section through an infected cordon or cane, and it appears as dark, necrotic wood. It is often accompanied by the presence of shoot dieback or dead spurs on the cordons. Presumably, wood infections are initiated primarily by germinated conidia on pruning wounds, and the ability of $P$. viticola mycelium to colonize woody tissue has been demonstrated on excised segments of woody shoots in the laboratory (40). Nonetheless, the initiation of wood infections by $P$. viticola in relation to the infection of green tissues is not clearly understood. For many years, when encountered in eastern North American vineyards, the wood canker symptom was thought to be due instead to Eutypa lata (20). Indeed, P. viticola is considered by some authors to be a facultative wound pathogen, able to colonize wood either directly through artificial or natural wounds in woody tissues (e.g., pruning wounds or crevices in the periderm) or following colonization of wounds in green tissues (e.g., natural tears in rapidly expanding shoots) and subsequent systemic growth of mycelia to adjacent woody tissues $(2,13,47)$.

Our objective was to determine whether the Diaporthe spp. causing wood cankers is $P$. viticola, the species which has been shown to cause the foliar symptoms of Phomopsis cane and leaf spot in the continental climate of eastern North America (32). Of 75 isolates recovered from leaf spots in a previous survey of the northeastern United States and southeastern Canada, only 1 isolate was identified not as $P$. viticola but, instead, as an unidentified Diaporthe sp. that was not pathogenic on green tissues in greenhouse inoculations (32). Of the 15 Diaporthe spp. isolated to date from wood cankers of grape, as identified primarily in parts of Europe, Australia, and South Africa, only P. amygdali, a pathogen of peach, has been shown to colonize shoots as aggressively as $P$. viticola (43). This latter finding came from a survey of wood cankers in vineyards in Mediterranean grape-growing climates of the southern hemisphere, and inoculations were conducted on green stems; therefore, it is difficult to make assumptions about wood- 
canker-causing Diaporthe spp. in eastern North America. Accordingly, we recovered and identified Diaporthe spp. from wood cankers in vineyards with a history of the typical foliar symptoms of Phomopsis cane and leaf spot. Also, we tested their pathogenicity in the greenhouse and the field on woody tissues, because past studies have evaluated the pathogenicity of Diaporthe spp. primarily on green tissues $(21,25,43)$.

Phomopsis spp. are well known as the asexual state of Diaporthe and is the state most commonly encountered by plant pathologists. Given the upcoming nomenclatural transition to one genus name for both sexual and asexual states of fungi (48), we use " $D i$ aporthe" throughout this article when referring to groups of isolates. "Diaporthe" or "Phomopsis" are used for known species placed in these genera by their currently accepted names. Unknown species will be referred to as "Diaporthe", which has nomenclatural priority by date over "Phomopsis".

\section{Materials and Methods}

Isolate collection. In total, 23 field sites were scattered across an area of approximately $13,000 \mathrm{~km}^{2}$. The U.S. state east of the Rocky Mountains with the highest grape acreage is New York (1); therefore, 5 of 23 sites were located in New York (Table 1). For areas with a similarly cold climate, sites were chosen in the nearby New England states of Connecticut, Massachusetts, New Hampshire, Rhode Island, and Vermont, and in the Canadian province of Quebec. Sites were also chosen in the Atlantic seaboard states of New Jersey and Virginia, in part because of their relatively warmer climate. Vineyards satisfied the following criteria: age $>10$ years, a history of foliar symptoms of Phomopsis cane and leaf spot, and the presence of shoot dieback or dead spurs on canes and cordons, which indicate the presence of a wood canker in some section of the permanent, woody structure of the vine (spur, cane, cordon, or trunk). From June to September in 2008 and 2009, one wood canker per vine was gathered from each of 3 to 10 vines per site (190 samples total).

Isolations were attempted from each wood canker. Four pieces of wood (approximately 2 by $5 \mathrm{~mm}$ ) were cut from the margin with a sterile scalpel, surface sterilized in $0.6 \%$ sodium hypochlorite ( $\mathrm{pH}$ 7.2) for $1 \mathrm{~min}$, rinsed twice in sterile distilled water for $1 \mathrm{~min}$, and plated on potato dextrose agar (PDA) (Difco Laboratories) amended with tetracycline $(1 \mathrm{mg} / \mathrm{liter})$. Isolation plates were incubated at $25^{\circ} \mathrm{C}$ in darkness for 14 days, and then subcultured to

Table 1. Diaporthe isolates (asexual state is Phomopsis) recovered from grapevine wood cankers, unless otherwise noted, in eastern North American vineyards with typical foliar symptoms of Phomopsis cane and leaf spot, in 2008 and 2009

\begin{tabular}{|c|c|c|c|c|c|}
\hline \multirow[b]{2}{*}{ Species, isolate ${ }^{w}$} & \multirow[b]{2}{*}{ Location } & \multirow[b]{2}{*}{ Host } & \multicolumn{3}{|c|}{ GenBank accession number } \\
\hline & & & ITS & EF1 $\alpha$ & Actin \\
\hline \multicolumn{6}{|c|}{ Diaporthe eres Nitschke } \\
\hline Pho12x & Geneva, NY & Vitis cinerea ${ }^{\mathrm{y}}$ & JN214572 & JN192166 & JN230370 \\
\hline Pho15 ${ }^{\mathrm{x}}$ & Westport, MA & V. vinifera 'Pinot blanc' & JN214574 & JN192168 & JN230372 \\
\hline Pho17 $7^{x}$ & Charlton, MA & V. vinifera 'Chardonnay' & JN214576 & JN192170 & JN230374 \\
\hline Pho21 ${ }^{\mathrm{x}}$ & Topsfield, MA & $\begin{array}{l}V \text {. vinifera } \times V \text {. rupestris } \times V \text {. lincecumii } \\
\text { 'Seyval blanc' }\end{array}$ & JN214580 & JN192174 & JN230378 \\
\hline Pho27 & Warren, CT & St. Emilion $\times$ Seibel 4986 'Vidal blanc' & JN214586 & JN192180 & JN230384 \\
\hline Pho29 & Topsfield, MA & $V$. vinifera $\times V$. rupestris $\times V$. lincecumii 'Aurore' & JN214588 & JN192182 & JN230386 \\
\hline Pho30 & Reigs Corner, QC, Canada & $\begin{array}{l}V \text {. vinifera } \times V \text {. rupestris } \times V \text {. lincecumii } \\
\text { Seyval blanc }\end{array}$ & JN214589 & JN192183 & JN230387 \\
\hline $\begin{array}{l}\text { Pho31 } \\
\text { Phomopsis cuppa }\end{array}$ & Dunham, QC, Canada & Seibel $2859 \times$ Seibel 4643 'Chelois' & JN214590 & JN192184 & JN230388 \\
\hline $\begin{array}{l}\text { Phomopsis cuppatea } \\
\text { E. Jansen. Lampr.\& Crous }\end{array}$ & & & & & \\
\hline Pho32 & Hector, NY & V. vinifera Chardonnay & JN214591 & JN192185 & JN230389 \\
\hline \multicolumn{6}{|c|}{ P. fukushii Tanaka \& S. Endo } \\
\hline Pho01 & Gales Ferry, CT & V. vinifera Chardonnay & JN214563 & JN192157 & JN230361 \\
\hline Pho02x & Guilford, CT & V. vinifera Chardonnay & JN214564 & JN192158 & JN230362 \\
\hline Pho04 ${ }^{\mathrm{x}}$ & North Stonington, CT & V. vinifera Chardonnay & JN214565 & JN192159 & JN230363 \\
\hline Pho05 & Little Compton, RI & $\begin{array}{l}\text { V. labruscana } \times V \text {. rupestris } \times V \text {. riparia } \\
\text { 'Chancellor' }\end{array}$ & JN214566 & JN192160 & JN230364 \\
\hline Pho0 $8^{x}$ & Southold, NY & V. vinifera 'Cabernet-Sauvignon' & JN214569 & JN192163 & JN230367 \\
\hline Pho09 & Cutchogue, NY & V. vinifera Cabernet-Sauvignon & JN214570 & JN192164 & JN230368 \\
\hline Pho $14^{\mathrm{x}}$ & South Hampton, NH & $\begin{array}{l}\text { V. labruscana } \times V \text {. rupestris } \times V \text {. riparia } \\
\text { 'Chancellor' }\end{array}$ & JN214573 & JN192167 & JN230371 \\
\hline Pho19x & Westport, MA & V. vinifera Chardonnay & JN214578 & JN192172 & JN230376 \\
\hline Pho20 $0^{x}$ & Warren, CT & $\begin{array}{l}V . \text { vinifera } \times V \text {. rupestris } \times V \text {. lincecumii } \\
\text { Seyval blanc }\end{array}$ & JN214579 & JN192173 & JN230377 \\
\hline $\mathrm{Pho} 22^{\mathrm{x}}$ & Westport, MA & V. vinifera 'Pinot noir' & JN214581 & JN192175 & JN230379 \\
\hline Pho23x ${ }^{x}$ & Hamilton Township, NJ & Interspecific Vitis hybridy & JN214582 & JN192176 & JN230380 \\
\hline \multicolumn{6}{|c|}{ P. viticola (Sacc.) Sacc. } \\
\hline Pho06 & Cambridge, VT & V. riparia $\times$ Landot noir 'Frontenac' & JN214567 & JN192161 & JN230365 \\
\hline Pho07 & Shelburne, VT & V. vinifera 'Zweigelt' & JN214568 & JN192162 & JN230366 \\
\hline Pho10 & Riverhead, NY & V. vinifera Cabernet-Sauvignon & JN214571 & JN192165 & JN230369 \\
\hline Pho16 & Charlton, MA & V. vinifera Chardonnay & JN214575 & JN192169 & JN230373 \\
\hline Pho18 & Lee, $\mathrm{NH}$ & Seibel $6905 \times$ Pinot noir 'Vignoles' & JN214577 & JN192171 & JN230375 \\
\hline $\mathrm{Pho} 24^{\mathrm{x}}$ & Hamilton Township, NJ & Interspecific Vitis hybrid ${ }^{y}$ & JN214583 & JN192177 & JN230381 \\
\hline Pho25x & Glendower, VA & V. riparia (wild Vitis $\mathrm{sp}$. outside of vineyard) & JN214584 & JN192178 & JN230382 \\
\hline Pho26 & Purchase, NJ & V. vinifera Chardonnay & JN214585 & JN192179 & JN230383 \\
\hline Pho28 & Front Royal, VA & V. vinifera 'Sauvignon blanc' & JN214587 & JN192181 & JN230385 \\
\hline PhoCT1L ${ }^{z}$ & Goshen, CT & V. vinifera Chardonnay (recovered from leaves) & JN214592 & JN192186 & JN230390 \\
\hline PhoCT2L $L^{z}$ & Goshen, CT & V. vinifera Chardonnay (recovered from leaves) & JN214593 & JN192187 & JN230391 \\
\hline
\end{tabular}

${ }^{\mathrm{w}}$ Species identities are based primarily on phylogenetic analysis of the internal transcribed spacer region (ITS) and, to a lesser extent, analyses of elongation factor subunit 1- $\alpha(\mathrm{EF} 1 \alpha)$ and actin, conidial dimensions, and colony growth. Isolates are a subset of 65 isolates, and were chosen as representatives for species-level identification.

${ }^{\mathrm{x}}$ Isolate formed $\alpha$ conidia in culture; species identity is based in part on conidial dimensions.

${ }^{\mathrm{y}}$ Vineyards were for research and breeding programs; grapevines were not commercial cultivars.

${ }^{\text {z }}$ Positive control; Phomopsis viticola isolate was recovered from leaf spots, as part of a previous study. 
PDA for colonies that were characteristic of Diaporthe spp. (colony white and cottony, with an irregular margin and concentric rings; spherical, black pycnidia scattered across colony and exuding cream-colored droplets of conidia (39). After 14 days, 65 Diaporthe isolates were purified by transferring hyphal tips to fresh plates of PDA, which were later arranged in 29 groups according to differences in colony morphology (growth rate, color, and frequency of pycnidia). From each of the 29 groups, one representative isolate was examined for species-level identification (Table 1). In preparation for DNA sequencing, genomic DNA was extracted from fresh mycelium after 7 days of incubation in potato dextrose broth at $25^{\circ} \mathrm{C}$ and $150 \mathrm{rpm}$ (18).

Phylogenetic analyses. Species-level identification was carried out, in part, through phylogenetic analyses of the 29 representative Diaporthe isolates gathered from wood cankers in vineyards. Comparisons were made to sequences of isolates from three publicly available culture collections: the American Type Culture Collection (ATCC), the U.S. National Fungus Collection (BPI), and the Centraalbureau voor Schimmelcultures (CBS) (Supplementary Table 1). Analyses included DNA sequences of 22 vouchered or type specimens of the following species: Diaporthe alleghaniensis isolate CBS 495.72 (ex-isotype); D. eres isolates ATCC 56789, FAU512 (BPI 747958), FAU526 (BPI 747960), AR3560 (BPI 749133), AR3561 (BPI 749134), AR3634 (BPI 840940), DP0397 (BPI 841335), DP0398 (BPI 841336), AR3723 (BPI 843611), CBS 524.82, CBS 109497 (BPI 747936), and CBS 109767 (BPI 748435); D. medusaea isolates CBS 109492 (BPI 748231) and CBS 109768 (BPI 747946); D. neotheicola isolate CBS 187.27 (ex-holotype of anamorph $P$. theicola); D. vaccinii isolates ATCC 32306, ATCC 56788, and CBS 160.32 (ex-holotype); P. fukushii isolates AR3477 (BPI 747945) and DP0438 (BPI 843626); and $P$. viticola isolate CBS 114016 (a.k.a. STE-U 2660; ex-epitype). Authentic isolates of P. fukushii (MAFF 625029, MAFF 625030, MAFF 625033, and MAFF 625034) from the National Institute of Agrobiological Sciences, Japan were included (14). Also included were DNA sequences of 76 additional isolates of known Diaporthe spp. originating from diverse hosts, from our laboratory culture collections. To determine whether the 29 Diaporthe isolates recovered from wood cankers were genetically similar to those previously identified from grape-namely, in the studies by Schilder et al. (32) and van Niekerk et al. (43) —BLASTn searches of GenBank were conducted, particularly of accessions originating from these two previous studies.

For all wood-canker isolates and type specimens isolates, we sequenced three nuclear loci (polymerase chain reaction [PCR] primers follow in brackets): a 476-bp section of the ribosomal DNA internal transcribed spacer region (ITS) (ITS1 and ITS4 [46]), a 429-bp section of the translational elongation factor subunit $1-\alpha$ gene $(E F 1 \alpha)(E F 1-728 F$ and EF1-986R [6]), and a 258-bp section of the actin gene (ACT547F [5'-TCGAGCTGTTTTYCGTAA GTC- $3^{\prime}$ ] and ACT768R [5'-CCCATRCCAATCATGATACTG-3']). The new actin primers were redesigned from the product of published primers ACT512F and ACT783R (6), the latter of which amplified two products (the same priming sites but very different internal sequences) for some isolates. PCR was performed with cycling parameters of $95^{\circ} \mathrm{C}$ for $2 \mathrm{~min} ; 35$ cycles at $95^{\circ} \mathrm{C}$ for $1 \mathrm{~min}$, $55^{\circ} \mathrm{C}$ for $1 \mathrm{~min}$, and $72^{\circ} \mathrm{C}$ for $1.5 \mathrm{~min}$; and 1 cycle at $72^{\circ} \mathrm{C}$ for 10 min. The presence and size of amplicons was confirmed by gel electrophoresis ( $1 \%$ agarose, $120 \mathrm{~V}, 25 \mathrm{~min}$ ), PCR products were purified (Exonuclease I, recombinant Shrimp Alkaline Phosphatase; Affymetrix), and PCR products were sequenced on an ABI 3730 Capillary Electrophoresis Genetic Analyzer (College of Biological Sciences Sequencing Facility, University of California, Davis). Sequences were manually edited in Sequencher 4.8 (Gene Codes Corporation) and manually aligned in Sequence Alignment Editor Se-Al 2.0 (28).

Parsimony analysis was conducted in PAUP* v. $4.0 \mathrm{~b} 10$ (34) using a heuristic search with 10 random-addition replicates and gaps treated as a fifth state, and bootstrap values were estimated from 1,000 replicates using the Branch-and-bound procedure. Bayesian analysis was conducted in MrBayes v. 3.2 .1 (30) (12,400,000 generations for ITS, 6,000,000 generations for EF1 $\alpha, 8,000,000$ generations for actin, and 22,800,000 generations for the combined data set of all three loci), with a sampling frequency of one tree every 100 generations, 15 heated and 1 cold chain, seven swaps at every swapping point, and temperature $\lambda$ of 0.1 , where chain $i$ is heated by raising its posterior probability to the power $1 /(1+i \lambda)$. All trees were unrooted. Publication-ready figures of tree files generated by PAUP* and MrBayes were created in FigTree v. 1.3.1 (29). Partition homogeneity tests conducted in PAUP* revealed significant incongruence between the three loci in all pairwise comparisons and, therefore, separate analyses were initially carried out on each locus. Nonetheless, a fourth set of parsimony and Bayesian analyses was carried out for a combined data set of all three loci, primarily for comparison with the results of the individual-locus analyses. For Bayesian analysis of the combined set, the data were partitioned into the three loci, parameters were unlinked across partitions, and partitions were allowed to evolve at different rates.

Morphology and growth studies. Incubation conditions that brought about pycnidium formation among the highest proportion of isolates were incubation on PDA with an overlay of an autoclaved grape leaf at $25^{\circ} \mathrm{C}$ in continuous fluorescent light for 14 days $(10,26,32)$. All isolates that developed pycnidia in culture produced $\alpha$ conidia that were characteristic of Phomopsis spp.: hyaline, fusiform, bi- or multi-guttulate, and aseptate $(21,39)$. $\beta$ Conidia were also characteristic of Phomopsis spp.: hyaline, filiform, straight or curved, eguttulate, and aseptate (39). Not all isolates produced $\alpha$ conidia and a smaller subset of these sporulating isolates also produced $\beta$ conidia. For isolates that produced $\alpha$ conidia under the incubation conditions described above, $\alpha$ conidia were gathered from two replicate PDA plates per isolate and mounted in water, and 30 conidia per plate were measured at $\times 1,000$ magnification. In addition, colony diameter was compared among three replicate plates per isolate, using the method of Farr et al. (11), which consisted of incubation on PDA at $25^{\circ} \mathrm{C}$ in darkness for 8 days. Analyses of variance (ANOVAs) were used to determine whether there were significant differences in conidial dimensions or colony diameter among isolates. Prior to ANOVA, homogeneity of variance was evaluated using Levene's test (5). To satisfy the assumption of homogeneity of variance, the following transformations were applied: reciprocal transformations to conidial width and reciprocal square root transformations to conidial length. ANOVA was performed using the MIXED procedure in SAS (v. 9.2; SAS Institute Inc.), and the effect of isolate was treated as a fixed effect. For significant effects $(P<0.05)$, means were compared by Tukey's tests. Reverse-transformed means and 95\% confidence limits are presented for data that were transformed prior to ANOVA.

Pathogenicity tests. To determine the ability of each species to cause wood cankers, two isolates per species (six isolates total) were inoculated onto the woody stems of potted Vitis labruscana Bailey Concord and V. vinifera L. 'Chardonnay' in the greenhouse. The following isolates were selected primarily based on their ability to sporulate consistently in culture: D. eres isolates Pho12 and Pho17, P. fukushii isolates Pho04 and Pho08, and P. viticola isolate Pho25. P. viticola isolate PhoCT2L, which was originally collected from leaf spots in a Connecticut vineyard and is known to be pathogenic to green tissues of grapevine, was included as a positive control. Each isolate had different actin, EF1 $\alpha$, and ITS sequences. Starting in April 2010, plants were propagated at 2-week intervals from dormant, two-node cuttings that were callused at $30^{\circ} \mathrm{C}$ and $100 \%$ relative humidity for 12 to 16 days in a mixture of sterile perlite and vermiculite $(1: 1, \mathrm{vol} / \mathrm{vol})$, rooted in sterile potting mix, and grown in the greenhouse for 6 months before inoculation. The experiment was performed three times, using three sets of plants propagated in three adjacent greenhouses.

In October 2010, plants were inoculated at 2-week intervals, starting with the set of plants that was propagated first in August 2010. The inoculation method was similar to that previously reported for trunk pathogens of grape (e.g., E. lata [33] and Lasio- 
diplodia theobromae [41]). A power drill was used to make a hole ( $2 \mathrm{~mm}$ in width by $3 \mathrm{~mm}$ in depth) in the woody stem of the rooted cuttings at a point approximately $3 \mathrm{~cm}$ below the uppermost node. Plants were inoculated (for each experiment: two cultivars $\times$ six isolates $\times$ nine replicate plants per cultivar-isolate combination $=$ 108 total inoculated plants) by pipetting $20 \mu \mathrm{l}$ of a conidial suspension into the drilled hole, then sealing this inoculation site with Vaseline (Unilever) and Parafilm (American National Can). Conidial suspensions were prepared by pipetting $1 \mathrm{ml}$ of sterile water onto the surface of a 14-day culture directly atop the mature pycnidia, suspending the conidia with gentle pipetting, and then diluting the $1-\mathrm{ml}$ suspension in $9 \mathrm{ml}$ of sterile water. The conidial concentration was determined with a hemacytometer and adjusted to $10^{6}$ conidia/ml. On the day of inoculation, serial dilutions $\left(10^{1}\right.$ to $10^{6}$ conidia/ ml) were plated on PDA and incubated at $25^{\circ} \mathrm{C}$ for 7 days, to confirm spore viability and inoculum concentrations among experiments. Noninoculated controls were mock inoculated (nine plants per cultivar $\times$ two cultivars $=18$ total noninoculated plants) with $20 \mu \mathrm{l}$ of sterile water. Plants were arranged in a randomized complete block design (RCBD) in each greenhouse, with three replicate plants of each cultivar-isolate treatment per each of three blocks. The north, central, and south benches of each greenhouse served as blocks in the RCBD.

Pathogenicity was evaluated at 1 year post inoculation, based on the length of wood lesions (i.e., wood cankers), which were revealed by cutting the stem longitudinally through the inoculation site. For each plant, measurements were made of the length of discolored wood radiating above and below the inoculation site (i.e., the wood lesion) and the total length of the woody stem (i.e., the original dormant cutting that the plant was propagated from; the stem that was inoculated). Recovery attempts of isolates inoculated onto the plants were made from wood at the margin of each lesion. The steps for recovery were as follows: green shoots and roots were cut away from the woody stem and discarded, all bark was scraped off the woody stem, the stem was surface sterilized in $1 \%$ sodium hypochlorite for $2 \mathrm{~min}$, and stem length was measured. Subsequently, the stem was cut in half longitudinally through the inoculation site, a caliper was used to measure the lesion length, and four pieces of wood (each approximately 2 by $5 \mathrm{~mm}$ ) were cut with a flame-sterilized scalpel from the distant margins of the lesion. Finally, the wood pieces were surface sterilized in $0.6 \%$ sodium hypochlorite $(\mathrm{pH}$ 7.2) for $1 \mathrm{~min}$, rinsed twice in sterile distilled water for $1 \mathrm{~min}$, and plated on PDA amended with tetracycline ( $1 \mathrm{mg} / \mathrm{liter})$.

Because stem length can potentially influence lesion length, and because the mean lengths of the two-node cuttings from which plants were propagated were longer for Concord (245.3 \pm 52.2 $\mathrm{mm}, n=189$ plants $)$ than for Chardonnay $(188.6 \pm 34.3 \mathrm{~mm}, n=$ 189 plants), there were two different measures of lesion length: total lesion length (millimeters) and lesion length expressed as a percentage of stem length. ANOVAs were used to determine whether there were significant differences in lesion length among the three experiments, between cultivars (Chardonnay and Concord), among isolates (noninoculated control, Pho04, Pho08, Pho12, Pho17, Pho25, and PhoCT2L), or based on the interactions of these main effects. Prior to ANOVA, homogeneity of variance across treatments was evaluated using Levene's test (5). To satisfy the assumption of homogeneity of variance, the following transformations were applied: a $\log _{10}$ transformation to lesion length (percentage of stem length) and a reciprocal square root transformation to total lesion length. ANOVAs were performed using the MIXED procedure in SAS v. 9.2, with all factors except block treated as fixed effects. To accommodate the fact that the mean stem lengths of the two cultivars varied by $23 \%$, and that this difference might also affect lesion length, the GROUP = cultivar option was used in a REPEATED statement to account for possible heterogeneous variances in ANOVA of total lesion length. For significant effects ( $F$ values with $P<0.05$ ), means were compared by Tukey's tests.

To determine the ability of each species to infect pruning wounds, which are the typical infection courts of trunk pathogens of grape (e.g., E. lata), we inoculated one isolate per species (D. eres Pho17, P. fukushii Pho04, and P. viticola Pho25) to Chardonnay and Concord in vineyards located in Geneva, NY and Fredonia, NY, respectively. The Chardonnay vineyard, established in 2004, was trained to bilateral cordons with five to eight three-bud spurs per cordon (10 to 16 spurs/vine). The Concord vineyard, established in 1985, was trained to bilateral cordons with 5 to 10 canes/cordon (10 to 20 canes/vine). Vineyards were pruned near the end of dormancy in April 2009 and 2010, corresponding to the pruning period for vineyards in this region. Concord was pruned such that the wounds were not positioned toward the ground, as is the typical orientation of this cultivar with its trailing growth habit, but, instead, were positioned upright to accommodate convenient application of the liquid inoculum. There were four vines per isolate and five pruning wounds per vine (16 total vines per vineyard per year, including noninoculated controls). Vines were distributed in a completely randomized design within each vineyard and different vines were inoculated each year. Each pruning wound was inoculated with $30 \mu \mathrm{l}$ of a conidial suspension (prepared as described above) 1 day after pruning and an equal number of vines was treated with $30 \mu \mathrm{l}$ of sterile water.

Spurs were collected from the pruning wounds in October following inoculation (6 months post inoculation). Recovery attempts were then made from the resulting wood cankers, as described above for recovery from wood cankers. Past studies involving inoculations of trunk pathogens to pruning wounds show that the extent of colonization is relatively limited and typically restricted to the adjacent node (e.g., 2 to $4 \mathrm{~cm}$ for $E$. lata; 45). In addition, the length of the inoculated tissues is limited (10 to $15 \mathrm{~cm}$ ), especially in spur-pruned cultivars such as Chardonnay. Furthermore, noninoculated controls also develop lesions due to the wounding and; therefore, lesion length is not always an informative measure of virulence. As such, we used percent recovery after inoculation as a measure of an isolate's ability to infect through a pruning wound. The percent recovery of each isolate was calculated as the percentage of pruning wounds from which an isolate was recovered out of the total number of inoculated pruning wounds per plant, and this was averaged across the four replicate plants per isolate (four plants $\times$ five pruning wounds per plant). The effects of isolate, year, and their interaction were tested separately for each cultivar, using an ANOVA performed with the GLIMMIX procedure in SAS v. 9.2, which utilizes the logit link function to accommodate binomial data (17). The SLICE option was used within the LSMEANS statement to compare percent recovery between years. Culture and conidial morphology were used to confirm that the isolates inoculated onto the pruning wounds in April were the same as those recovered from the resulting wood lesions the following October. From a subset of the noninoculated controls from which Diaporthe spp. were recovered, we sequenced ITS, using the methods described above for phylogenetic analyses.

\section{Results}

Isolate collection. From a total of 190 wood cankers, we recovered 65 Diaporthe isolates. Wood cankers were found at each of the 23 field sites and in every vine that was sampled. A Diaporthe isolate was recovered from at least one vine per field site. Wood cankers from which a Diaporthe isolate was not recovered were colonized by other Ascomycete genera (Botryosphaeria, Cadophora, Diatrypella, Diplodia, Eutypa, Eutypella, Lasiodiplodia, Neofusicoccum, Phaeoacremonium, and Phaeomoniella). Thirteen cultivars of grape were sampled among the field sites. Seven of these were hybrids of $V$. vinifera $\times$ North American Vitis spp., which are unique to this grape-growing region of eastern North America. After grouping the 65 Diaporthe isolates according to differences in the colony morphology, a subset of 29 representative isolates was selected for species-level identification (Table 1).

Phylogenetic analyses. Bayesian and parsimony analyses produced similar topologies, in analyses of each locus alone (ITS, EF1 $\alpha$, or actin) or combined, for sequences of our 29 isolates, 20 type specimens, and 82 other known specimens (131 total taxa). 
The combined data set (Fig. 1) and ITS alone (Supplementary Figure 1) were most informative; unknown isolates grouped with type specimens into distinct, well-supported clades. Parsimony analysis of the combined data set yielded 31,200 equally parsi- monious trees ( 380 parsimony-informative characters out of a total of 1,128 aligned characters; Fig. 1).

Of the 29 unknown isolates, 9 clustered with the type specimen of $P$. viticola (CBS 114016) and with the two P. viticola isolates

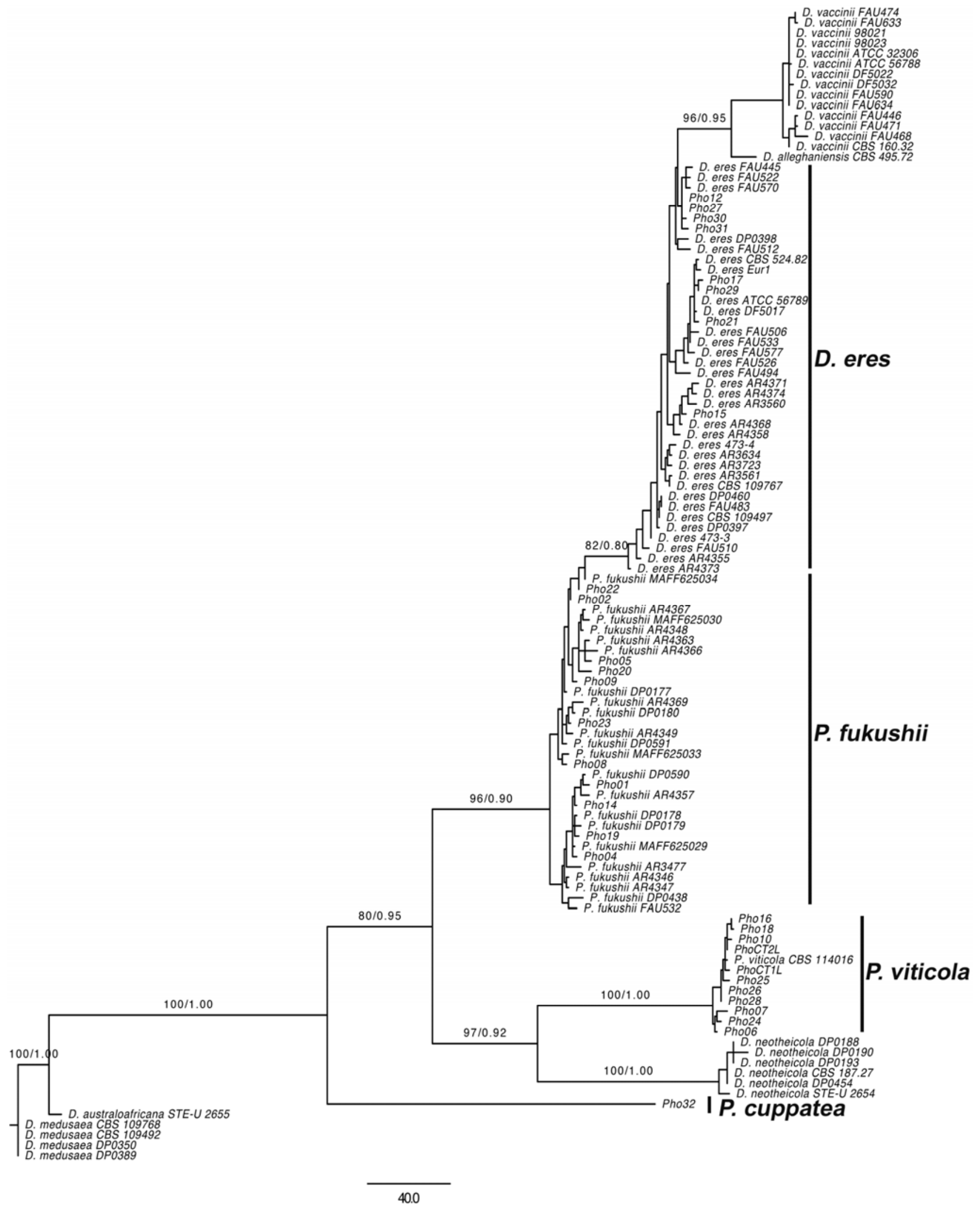

Fig. 1. One of 31,200 equally parsimonious trees (consistency index $=0.72$, retention index $=0.92$, rescaled consistency index $=0.6$, and length $=492$ ) created by a heuristic search with 10 random-addition replicates of internal transcribed spacer region, elongation factor subunit 1- $\alpha$, and actin sequences. Branch labels represent bootstrap support values $(\geq 80)$ over Bayesian posterior probability values $(\geq 0.80)$. Diaporthe isolates that we recovered from eastern North American vineyards have labels including 'Pho', whereas all other isolates were type specimens obtained by our lab from publicly available culture collections. 
that we previously recovered from leaves with foliar symptoms (PhoCT1L and PhoCT2L), in phylogenetic analyses of the combined data set (Fig. 1) and ITS. The remaining 19 isolates clustered with known isolates of either $D$. eres (e.g., ATCC 56789) or $P$. fukushii (e.g., MAFF 625029). Based on BLASTn searches of GenBank, all eight isolates that clustered with $D$. eres shared high ITS sequence identity (e.g., ranging from $98 \%$ identity with $0 \%$ gaps for Pho12 to $100 \%$ identity with $0 \%$ gaps for Pho21) to an unnamed Diaporthe sp. from grape in South Africa, Phomopsis sp. 6 (isolate STE-U 5466, accession AY485734; 43). All 11 isolates that clustered with $P$. fukushii shared high ITS sequence identity (e.g., ranging from $97 \%$ identity with $1 \%$ gaps for Pho05 to $98 \%$ identity with $0 \%$ gaps for Pho01) to another unnamed species from grape in South Africa, Phomopsis sp. 4 (isolate STE-U 5464, accession AY485726; 43), and an unnamed Diaporthe isolate from grape in the Midwestern United States (isolate $\mathrm{OH} 48$, accession AY745087; 32).

Compared with ITS, EF1 $\alpha$ and actin were more variable across all taxa, in terms of the relative proportion of variable characters, but were less variable among taxa within certain clades (data not shown). ITS had 89 parsimony-informative characters out of a total of 476 aligned characters, EF1 $\alpha$ had 215 parsimony-informative characters out of a total of 429 aligned characters, and actin had 93 parsimony-informative characters out of a total of 258 aligned characters. Parsimony analysis yielded 24,300, 8,692, and 24 equally parsimonious trees for ITS, EF1 $\alpha$, and actin, respectively (data not shown). The nine isolates that clustered with type specimens of $P$. viticola in analysis of ITS also clustered with $P$. viticola in analyses of EF1 $\alpha$ and actin (data not shown). In contrast, the $P$. fukushii and D. eres clades, which were represented as two separate, well-supported clades based on analysis of the combined data set (Fig. 1) and ITS, were poorly supported in analyses of EF1 $\alpha$ and actin (data not shown). In fact, D. eres Pho15 had an actin sequence identical to three P. fukushii isolates (Pho02, Pho09, and Pho23).

Table 2. Dimensions of $\alpha$ conidia and colony diameter of Diaporthe isolates, which sporulated in culture, from eastern North American vineyards

\begin{tabular}{lccc}
\hline & \multicolumn{3}{c}{$\alpha$ Conidial dimensions $^{\mathbf{x}}$} \\
\cline { 2 - 4 } Species, isolate & $\begin{array}{c}\text { Length } \\
(\boldsymbol{\mu m})\end{array}$ & $\begin{array}{c}\text { Width } \\
(\boldsymbol{\mu m})\end{array}$ & $\begin{array}{c}\text { Colony diameter } \\
(\mathbf{m m}) \mathbf{y}\end{array}$ \\
\hline $\begin{array}{l}\text { Diaporthe eres } \\
\text { Pho12 }\end{array}$ & $6.9 \mathrm{ab}$ & $2.0 \mathrm{ab}$ & $56.1 \mathrm{c}$ \\
Pho15 & $7.6 \mathrm{bc}$ & $2.0 \mathrm{ab}$ & $62.5 \mathrm{~cd}$ \\
Pho17 & $7.6 \mathrm{bc}$ & $2.4 \mathrm{c}$ & $77.3 \mathrm{de}$ \\
Pho21 & $7.7 \mathrm{bc}$ & $2.2 \mathrm{~b}$ & $79.0 \mathrm{de}$ \\
Phomopsis fukushii & & & \\
Pho02 & $6.7 \mathrm{a}$ & $2.3 \mathrm{bc}$ & $32.8 \mathrm{ab}$ \\
Pho04 & $7.3 \mathrm{~b}$ & $2.1 \mathrm{~b}$ & $60.3 \mathrm{~cd}$ \\
Pho08 & $6.7 \mathrm{a}$ & $1.9 \mathrm{a}$ & $82.7 \mathrm{e}$ \\
Pho14 & $7.4 \mathrm{~b}$ & $2.1 \mathrm{~b}$ & $85.0 \mathrm{e}$ \\
Pho19 & $6.5 \mathrm{a}$ & $2.4 \mathrm{c}$ & $54.5 \mathrm{bc}$ \\
Pho20 & $6.6 \mathrm{a}$ & $2.5 \mathrm{c}$ & $80.3 \mathrm{e}$ \\
Pho22 & $7.5 \mathrm{bc}$ & $2.3 \mathrm{bc}$ & $83.2 \mathrm{e}$ \\
Pho23 & $7.3 \mathrm{~b}$ & $2.3 \mathrm{bc}$ & $67.8 \mathrm{~d}$ \\
P. viticola & & & \\
Pho24 & $10.5 \mathrm{e}$ & $2.7 \mathrm{~d}$ & $24.3 \mathrm{a}$ \\
Pho25 & $8.6 \mathrm{~d}$ & $2.6 \mathrm{~cd}$ & $51.7 \mathrm{bc}$ \\
PhoCT1L & $10.6 \mathrm{e}$ & $3.5 \mathrm{e}$ & $48.8 \mathrm{bc}$ \\
PhoCT2L & $10.5 \mathrm{e}$ & $3.0 \mathrm{de}$ & $44.0 \mathrm{~b}$ \\
\hline
\end{tabular}

${ }^{x}$ Conidial dimensions are the means of 30 conidia per plate, averaged across two potato dextrose agar (PDA) plates. Measurements taken on conidia that formed from colonies grown atop an overlay of an autoclaved grape leaf on PDA after 14 days of incubation at $25^{\circ} \mathrm{C}$ in continuous fluorescent light. Means in the same column with the same letter are not significantly different (Tukey's test, $P \leq 0.05$ ).

${ }^{y}$ Colony diameters are the means of three observations, averaged across three PDA plates. Measurements taken on PDA after 8 days incubation at $25^{\circ} \mathrm{C}$ in darkness.

${ }^{\mathrm{z}}$ Used for pathogenicity tests in the greenhouse.
A single isolate, Pho32, did not share high sequence similarity with any known specimens. Based on the results of BLASTn searches, Pho32 shared the highest ITS (95\% identity with $0 \%$ gaps) and EF1 $\alpha$ (76\% identity with $9 \%$ gaps) sequence similarities with $P$. cuppatea E. Jansen, Lampr. \& Crous (isolate R433R; accessions AY339322 and AY339354, respectively), a species identified from Aspalathus linearis in South Africa (44). This isolate did not sporulate in culture. Therefore, we cannot compare its conidial dimensions with those of the species description ([10] $12-13[-14] \times[3-] 4[-5] \mu \mathrm{m} ; 44)$. Thus, its identity as $P$. cuppatea is putative.

Morphology and growth studies. Of the 29 isolates, conidial $(\alpha)$ dimensions of the 16 sporulating isolates varied significantly $(P<0.0001$ for length and width, in separate ANOVAs; Table 2$)$. Conidial dimensions distinguished $P$. viticola isolates from all others. The conidia of both $P$. viticola isolates (Pho24 and Pho25) were within the range of the description ([7-]9.5-10.5[-13] $\times$ [1.5-]2-3[-3.5] $\mu \mathrm{m} ; 21$ ), and Pho24 had conidia with the same dimensions as those of the positive controls (PhoCT1L and PhoCT2L). The conidia of the remaining 12 isolates, which were identified as $P$. fukushii and D. eres in phylogenetic analyses (Fig. 1), were all shorter than those of $P$. viticola (Fig. 2). There was significant overlap in conidial dimensions between some isolates of $P$. fukushii and D. eres, which had ranges of 6.5 to $7.5 \times 2.0$ to $2.5 \mu \mathrm{m}$ and 6.9 to $7.7 \times 2.0$ to $2.4 \mu \mathrm{m}$, respectively. Nonetheless, these dimensions are within the ranges of the species descriptions of P. fukushii $(6.1$ to $6.9 \times 2.1$ to $2.7 \mu \mathrm{m} ; 14)$ and $P$. oblonga, the accepted anamorph of $D$. eres ( 6 to $7 \times 3 \mu \mathrm{m} ; 36$ ).

Colony diameter after 8 days varied significantly $(P<0.0001)$ among the 16 sporulating isolates. However, significant overlap between species confounded their delineation. D. eres tended to be of greater diameter (56 to $79 \mathrm{~mm}$ ) than $P$. viticola ( 24 to $52 \mathrm{~mm}$ ). $P$. fukushii had the largest range ( 33 to $85 \mathrm{~mm}$ ), which overlapped with those of $D$. eres and $P$. viticola. Because the colony diameters and conidial dimensions were useful for delineating only certain species, coupled with the fact that $\mathrm{EF} 1 \alpha$ and actin did not resolve even the known isolates of $P$. fukushii and D. eres, the identities of the non- $P$. viticola isolates are based primarily on phylogenetic analysis of ITS and the combined data set.

Pathogenicity tests. All isolates of P. viticola, P. fukushii, and $D$. eres that were inoculated onto potted plants in the greenhouse

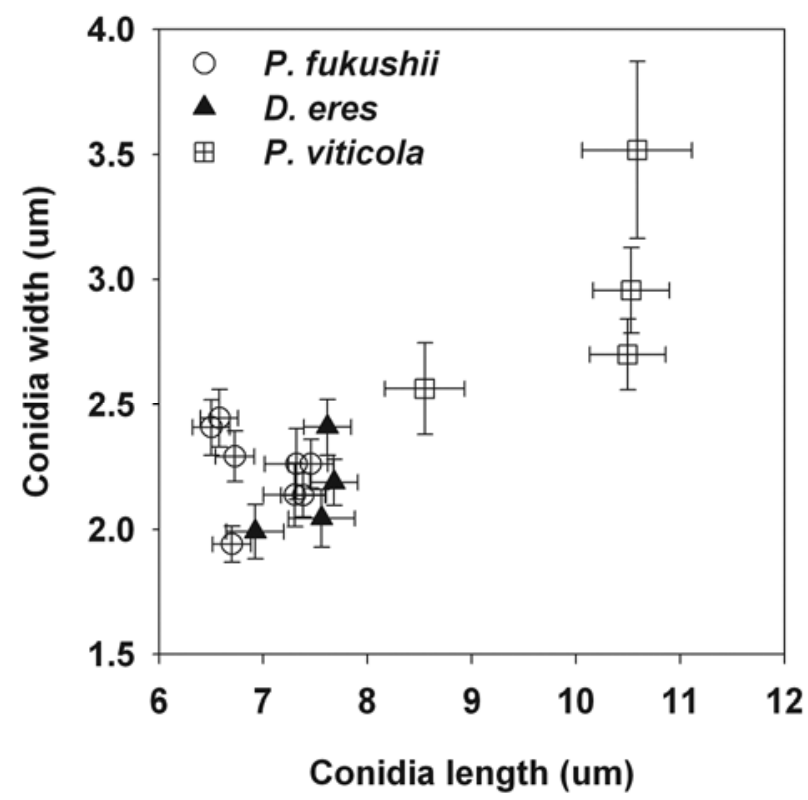

Fig. 2. Scatterplot of dimensions of $\alpha$ conidia of Diaporthe isolates from eastern North American vineyards. Each point is the mean of 30 conidia per plate, averaged across two potato dextrose agar plates. Error bars represent $95 \%$ confidence limits from two separate analyses of variance for conidial length or width. Points with overlapping error bars are not significantly different at $P \leq 0.05$, Tukey's test. 
were pathogenic, based on the fact that the lesions in the woody stems were significantly longer than those of noninoculated plants (Table 3; Fig 3). The wood immediately surrounding the inoculation sites of noninoculated plants was discolored but the discoloration was restricted $(3.5 \mathrm{~mm} ; n=54$ plants, averaged across cultivars) and Diaporthe spp. were not recovered from it. From lesions of all inoculated plants, we recovered colonies that matched the culture morphology and conidial dimensions of isolates inoculated onto the plants (data not shown). There were no apparent foliar symptoms that are typically associated with a wood canker in the field, such as stunting or dieback of the green shoots.

ANOVAs of lesion length expressed as either total lesion length or percentage of stem length gave similar results (Table 3). In all three experiments, the lesions were larger in Chardonnay versus Concord but the magnitude of this difference was lower in experiment 1 (4.9 versus $3.3 \%$ of stem length, $n=63$ plants per cultivar, averaged across isolates) than in experiment 2 (5.2 versus $3.0 \%$ of stem length, $n=63$ plants per cultivar, averaged across isolates) and experiment 3 (7.0 versus $2.6 \%$ of stem length, $n=63$ plants per cultivar, averaged across isolates); hence the significant experiment-cultivar effect on both measures of lesion length (Table 3). For all isolates, Chardonnay developed significantly larger lesions than Concord but the magnitude of this cultivar difference was lower for P. viticola isolate PhoCT2L (mean lesion lengths of 13.4 versus $12.5 \mathrm{~mm}$ for Chardonnay and Concord, respectively; $n=27$ plants per cultivar) than for the five other isolates (e.g., P. viticola Pho25, 17.6 versus $10.4 \mathrm{~mm}$ for Chardonnay and Concord, respectively; $n=27$ plants per cultivar). However, regardless of the measure of lesion length and these significant interaction effects, Chardonnay developed significantly larger lesions than Concord across all three experiments and all six isolates, and it suggests that Chardonnay may be more susceptible than Concord to wood infection by the three species.

Both $P$. viticola isolates, PhoCT2L (positive control and leafspot isolate) and Pho25 (wood-canker isolate), caused the largest lesions (Fig. 3), with mean lesion lengths of 13 and $14 \mathrm{~mm}(n=$ 54 plants, averaged across cultivars), respectively. All four $P$. fukushii and $D$. eres isolates caused lesions that were significantly smaller than those of $P$. viticola (Fig. 3); therefore, these two species also appear to be pathogenic but are less aggressive on Chardonnay and Concord. Nonetheless, even the most aggressive isolate tested, $P$. viticola Pho25, caused a mean lesion length of $14 \mathrm{~mm}$ ( $7.4 \%$ of stem length; $n=54$ plants, averaged across cultivars), and this was measured after 1 year of incubation in the greenhouse.

Table 3. $F$ values from analyses of variance for lesion lengths at 1 year post inoculation, in the woody stems of potted grapevines 'Concord' and 'Chardonnay' inoculated in the greenhouse with Diaporthe eres (Pho12 or Pho17), Phomopsis fukushii (Pho04 or Pho08), P. viticola (Pho25 or PhoCT2L), or sterile water (noninoculated controls) in three repetitions of the experiment

\begin{tabular}{|c|c|c|c|}
\hline \multirow[b]{2}{*}{ Source $^{y}$} & \multirow[b]{2}{*}{$\mathbf{N d f}^{\mathbf{z}}$} & \multicolumn{2}{|c|}{$F$ values $^{x}$} \\
\hline & & Stem $(\%)$ & Total \\
\hline Experiment & 2 & 0.8 & $3.1 *$ \\
\hline Cultivar & 1 & $97.8 * * *$ & $100.4 * * *$ \\
\hline Isolate & 6 & $29.7 * * *$ & $57.8 * * *$ \\
\hline Experiment $\times$ cultivar & 2 & $7.4^{* *}$ & $4.5^{*}$ \\
\hline Experiment $\times$ isolate & 12 & 1.2 & 1.6 \\
\hline Cultivar $\times$ isolate & 6 & 1.4 & $6.2 * * *$ \\
\hline Experiment $\times$ cultivar $\times$ isolate & 12 & 0.6 & 1.5 \\
\hline
\end{tabular}

${ }^{x}$ Denominator degrees of freedom are 332 for all main and interaction effects (Kenward-Roger denominator degrees of freedom method); *, **, and $* * *$ indicate significance at $P<0.05,0.001$, and 0.0001 , respectively.

Lesion length was expressed as a percentage of total stem length (Stem $[\%]$ ) or as the exact lesion length (Total).

${ }^{y}$ Sources of variation: Repetitions of the experiment (experiment), Chardonnay or Concord (cultivar), and noninoculated, Pho04, Pho08, Pho12, Pho17, Pho25, or PhoCT2L (isolate).

${ }^{\mathrm{z}}$ Numerator degrees of freedom.
Inoculations to pruning wounds of Chardonnay and Concord in the field showed that isolates of D. eres, $P$. fukushii, and P. viticola are capable of colonizing woody tissues under natural climatic conditions (Table 4). For separate analyses of Chardonnay and Concord, ANOVAs showed a significant species-year interaction $(P=0.02$ and 0.001 , respectively). There were relatively high levels of natural infection in 2009, as indicated by $40 \%$ recovery from the noninoculated controls of both cultivars, compared with 2010 (Table 4). The $D$. eres and $P$. viticola isolates recovered from noninoculated controls, as confirmed by sequencing the ITS region, were presumably from natural sources. In Chardonnay, percent recovery of all three species was consistently high in both years whereas, in Concord, recovery from all treatments decreased significantly in 2010. This is in spite of the fact that the inoculum concentrations and viability were the same from site to site and year to year. Given this unexpected and inexplicable variability, this field experiment is best interpreted at the qualitative level, from which we can say that each Diaporthe sp. infected inoculated pruning wounds.

\section{Discussion}

From 23 eastern North American vineyards, P. viticola, $P$. fukushii, D. eres, and putative $P$. cuppatea were recovered from wood cankers. Because these vineyards had a history of the foliar symptoms of Phomopsis cane and leaf spot, our findings suggest that the wood-canker symptom is common but may not always be due to $P$. viticola, the species shown to be the causal agent of the foliar symptoms (32). Our finding of wood-infecting isolates of $P$. viticola in eastern North America is supported by reports of $P$. viticola isolated from wood cankers in grape-growing regions with a Mediterranean climate (South Africa [43] and California [42]), where the foliar symptoms are rare relative to wood cankers. In contrast, the foliar symptoms are often very widespread in eastern North America, where rains early in the growing season are common (22). In eastern North America, the majority of vineyard acreage is dominated by juice and preserve grape cultivars, which are coldtolerant cultivars of the North American species $V$. labruscana (e.g., Concord), hybrids of $V$. labruscana $\times$ the European wine grape $V$. vinifera (e.g., 'Niagara'), and more complex hybrids of

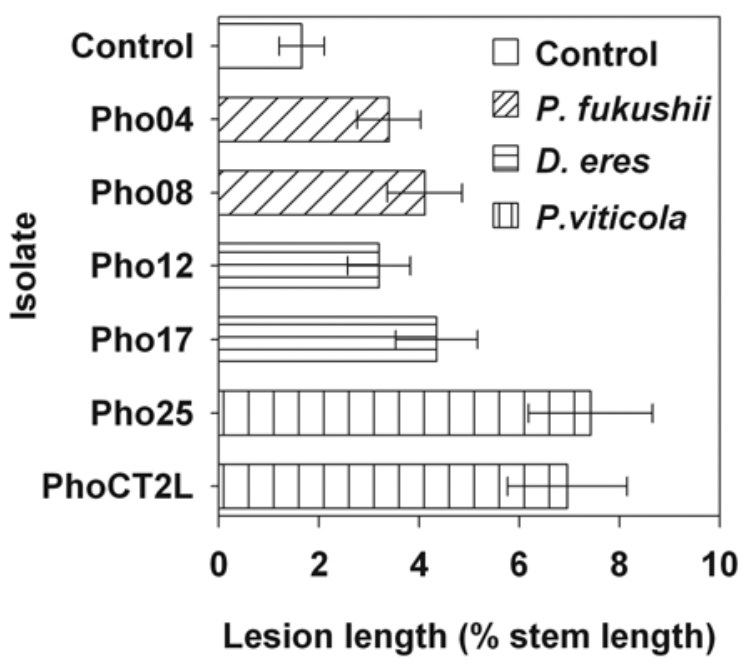

Fig. 3. Average length of lesions (percentage of stem length) caused on woody stems of potted plants in the greenhouse at 1 year post inoculation by five Diaporthe isolates (Pho04, Pho08, Pho12, Pho17, and Pho25) that were originally recovered from wood cankers from eastern North American vineyards. PhoCT2L (Phomopsis viticola), originally recovered from leaf spots, was included as a positive control. Error bars represent $95 \%$ confidence limits. Each column is the mean of 54 observations summed over three replicate experiments and two grape cultivars, 'Chardonnay' and 'Concord', which had mean stem lengths $( \pm$ half the $95 \%$ confidence interval) of $188.6 \pm 34.3$ and $245.3 \pm 52.2 \mathrm{~mm}$, respectively. Columns with overlapping error bars are not significantly different at $P \leq 0.05$, Tukey's test. 
these two species with additional North American Vitis spp. (e.g., 'Cayuga White'). As such, our field sites represented a sampling from a broader diversity of Vitis germplasm, relative to past studies on Diaporthe spp. of grape $(32,43)$.

The development of lesions on the woody stems of Concord and Chardonnay in the greenhouse demonstrates that $P$. viticola, $P$. fukushii, and D. eres can cause wood cankers. Furthermore, high recovery rates of all three species from vines inoculated in the field confirm their ability to colonize pruning wounds under natural conditions. This study appears to be the first to confirm wood infection by $P$. viticola, $P$. fukushii, and $D$. eres on the woody stem of an intact plant. Indeed, previous pathogenicity testing of Diaporthe spp. on grape focused on green shoots $(21,25,43)$, likely due to the very apparent symptoms on such tissues in the field. The greater susceptibility of green tissues to $P$. viticola is made more apparent by comparing the lesions we measured on woody stems after 1 year (14 $\mathrm{mm}$ for the most aggressive isolate) and those reported from green shoots after only 7 weeks $(18 \mathrm{~mm})(25)$.

Our isolates of $P$. fukushii and $D$. eres had conidial dimensions similar to those of Phomopsis sp. $4([6-] 7-9[-10] \times 2-2.5[-3] \mu \mathrm{m})$ and Phomopsis sp. 6 ([6-]7-9[-10] × 2-2.5 $\mu \mathrm{m})$, respectively (43). Our isolates of $P$. fukushii also had high ITS sequence identity to the only isolate not identified as $P$. viticola, $\mathrm{OH} 48$, in a survey of Diaporthe spp. on green tissues of grape (32). As such, we propose the identifications of Phomopsis sp. 4 (43) and isolate OH-48 (32) as P. fukushii and Phomopsis sp. 6 (43) as D. eres. Interestingly, OH-48 was not virulent on green tissues of 'Seyval' (32). van Niekerk et al. (43) had similar findings with South African isolates of Phomopsis spp. 4 and 6, which were weakly or not virulent on green shoots of 'Chenin Blanc' or 'Pinotage'. Thus, it is possible that $P$. fukushii and $D$. eres are not pathogenic on green tissues.

Our findings of wood-infecting $P$. viticola isolates in vineyards with foliar symptoms, coupled with positive recovery of $P$. viticola from vines inoculated in the field, suggest that colonization of pruning wounds, an important infection court for other woodinfecting fungi of grape (E. lata; 16), may also be important in the epidemiology of Phomopsis cane and leaf spot. However, it is also possible that wood cankers result from systemic spread of infections initiated on green tissues, as is the case for Botryosphaeria dothidea, causal fungus of panicle and shoot blight of pistachio (19). Thus, without knowing that it is the same $P$. viticola isolates

Table 4. Recovery of Diaporthe isolates inoculated onto pruning wounds of Vitis vinifera 'Chardonnay' in Geneva, NY and V. labruscana 'Concord' in Fredonia, $\mathrm{NY}^{\mathrm{x}}$

\begin{tabular}{|c|c|c|}
\hline \multirow[b]{2}{*}{ Cultivar, isolate ${ }^{\mathrm{z}}$} & \multicolumn{2}{|c|}{ Recovery $(\%)^{y}$} \\
\hline & 2009 & 2010 \\
\hline \multicolumn{3}{|l|}{ Chardonnay } \\
\hline Diaporthe eres $\mathrm{Pho} 12$ & 84 & 80 \\
\hline Phomopsis fukushii Pho04 & 75 & 85 \\
\hline P. viticola $\mathrm{Pho} 25$ & 61 & 78 \\
\hline Noninoculated control & 40 & $4 * *$ \\
\hline \multicolumn{3}{|l|}{ Concord } \\
\hline D. eres $\mathrm{Pho} 12$ & 100 & $40 * *$ \\
\hline P. fukushii Pho04 & 100 & $61^{*}$ \\
\hline P. viticola $\mathrm{Pho} 25$ & 64 & $16^{*}$ \\
\hline Noninoculated control & 40 & $4 * *$ \\
\hline
\end{tabular}

x Plants were inoculated 1 day after pruning in April 2009 and 2010, and recovery attempts were made in the following October (6 months post inoculation). Each value is the mean of four plants, and each plant had five inoculated pruning wounds.

y Percent recovery was calculated as the proportion of pruning wounds from which an isolate was recovered out of the total number of pruning wounds inoculated per plant. For the noninoculated controls, recovery refers to fungi that naturally colonized the pruning wounds; $*$ and $* *$ indicate significant differences at $P<0.05$ and 0.01 , respectively, between years for a given isolate. Significance levels are based on the tests of effect slices for the year-isolate interaction, sliced by isolate, following analysis of variance using the GLIMMIX procedure in SAS.

${ }^{\mathrm{z}}$ Species and isolate inoculated. causing both foliar symptoms and wood cankers, it is premature to make changes to current control practices. Nonetheless, if direct colonization of pruning wounds is important in the epidemiology of this disease, different control strategies may be needed. Currently, eastern North American growers apply calcium polysulfide in the dormant season, followed by spring applications of a protectant fungicide (e.g., mancozeb; 23). This approach may minimize wood cankers if they result from systemic spread of $P$. viticola from green tissues but not if pruning wounds are infected directly. In California, wood colonization by $P$. viticola and other wood-canker fungi is prevented by delaying pruning to when rain is less frequent and, thus, there is less inoculum (45) or by dormant-season application directly to pruning wounds of a protectant fungicide (e.g., thiophanate methyl in California; 4). Growers in eastern North America do not typically protect pruning wounds, because the very apparent risk of infection of green shoots overshadows possible infection of pruning wounds.

We rely heavily on DNA sequence data for Diaporthe spp. identification, as have others $(7,10,35)$. This is due, in part, to the rarity of perithecia in the field, the paucity of morphological characteristics to differentiate species in culture, and the fact that Diaporthe spp. are known to stop sporulating, as was the case for $50 \%$ of our isolates, after repeated subculture or long-term storage (11). Even among our sporulating isolates, conidial dimensions overlapped between D. eres and P. fukushii; therefore, a DNA-based approach was more definitive. Alternatively, it is possible to mate isolates and induce production of perithecia, which are variable in the genus Diaporthe. However, success is dependent, in part, on having the fortune to encounter a homothallic species or happening upon different mating types of a heterothallic species (38). In our case, which is complicated by the fact that $D$. eres and $P$. fukushii are closely related and their species concepts are poorly resolved (15), the inclusion of reference isolates was our best attempt to compensate for the lack of taxonomic characters in the genus $\mathrm{Di}$ aporthe.

That said, a reliance on DNA sequence data has its drawbacks. Indeed, phylogenetic analysis of ITS grouped D. eres and $P$. fukushii into separate clades, whereas analyses of EF1 $\alpha$ or actin grouped $D$. eres and $P$. fukushii into a single clade. There are conflicting results in the literature on the utility of these loci for $\mathrm{Di}$ aporthe spp. identification. For example, phylogenetic analysis of ITS in order to identify an unnamed Diaporthe isolate surprisingly divided its single-ascospore progeny into two distant clades but these same progeny were correctly grouped into a single clade through analysis of EF1 $\alpha$ (31). In contrast, van Rensberg et al. (44) found concordance between ITS and EF1 $\alpha$ in their identification of Diaporthe spp. causing dieback of A. linearis. Thus, the utility of ITS for species-level identification, especially in large-scale, environmental-sequencing efforts that utilize a barcoding approach, is dependent on thorough morphological descriptions of reference isolates (3).

The taxonomy of the genus Diaporthe has long been based on host associations (39). P. viticola is known only from grape, for example (12). Nonetheless, there are examples of Diaporthe spp. that are pathogenic on more than one species, such as P. amygdali, which was described from almond (37) but is pathogenic on grape (43). In contrast, $D$. eres is reported from approximately 300 species (12), and the results of our pathogenicity tests have extended the host range of this species to include grape. P. fukushii is reported from Asia and only from pome fruit (Pyrus and Malus spp.; 12). Our findings of $P$. fukushii as pathogenic on grape, coupled with morphological and ITS sequence similarity to South African isolates of unnamed species Phomopsis spp. 4 and 6 in (43), expand the host and geographic range of $P$. fukushii.

\section{Acknowledgments}

We thank B. Mackey (USDA-ARS, Pacific West Area Statistician) for guidance with experimental design and statistical analyses; T. J. Michailides (University of California, Davis, and Kearney Agricultural Center, Parlier, CA) and M. Nita (Virginia Polytechnic Institute and State University, Winchester) for kindly providing reviews of this manuscript; all extension specialists, viticulturists, and 
vineyard owners for their cooperation; and M. Barr, D. Farr, S.-K. Hong, W. Jaklitsch, W. Kandula, A. Phillips, and M. Putnam for specimens or cultures from a variety of hosts and localities.

\section{Literature Cited}

1. Anonymous. 2011. Noncitrus Fruits and Nuts 2010 Preliminary Summary. United States Department of Agriculture, National Agricultural Statistics Service, Washington, DC.

2. Barnes, E. H. 1963. Incidence of systemic dead-arm and its relation to topography in Michigan vineyards. Plant Dis. Rep. 47:872-874.

3. Begerow, D., Nilsson, H., Unterseher, M., and Maier, W. 2010. Current state and perspectives of fungal DNA barcoding and rapid identification procedures. Appl. Microbiol. Biotechnol. 87:99-108.

4. Bester, W., Crous, P. W., and Fourie, P. H. 2007. Evaluation of fungicides as potential grapevine pruning wound protectants against Botryosphaeria species. Australas. Plant Pathol. 36:73-77.

5. Box, G. E. P., Hunter, W. G., and Hunter, J. S. 1978. Statistics for Experimenters: An Introduction to Design, Data Analysis, and Model Building. Wiley, New York.

6. Carbone, I., and Kohn, L. M. 1999. A method for designing primer sets for speciation studies in filamentous ascomycetes. Mycologia 91:553-556.

7. Diogo, E. L. F., Santos, J. M., and Phillips, A. J. L. 2010. Phylogeny, morphology and pathogenicity of Diaporthe and Phomopsis species on almond in Portugal. Fungal Divers. 44:107-115.

8. Erincik, O., Madden, L. V., Ferree, D. C., and Ellis, M. A. 2001. Effect of growth stage on susceptibility of grape berry and rachis tissues to infection by Phomopsis viticola. Plant Dis. 85:517-520.

9. Erincik, O., Madden, L. V., Ferree, D. C., and Ellis, M. A. 2003. Temperature and wetness-duration requirements for grape leaf and cane infection by Phomopsis viticola. Plant Dis. 87:832-840.

10. Farr, D. F., Castlebury, L. A., and Pardo-Schultheiss, R. A. 1999. Phomopsis amygdali causes peach shoot blight of cultivated peach trees in the southeastern United States. Mycologia 91:1008-1015.

11. Farr, D. F., Castlebury, L. A., and Rossman, A. Y. 2002. Morphological and molecular characterization of Phomopsis vaccinii and additional isolates of Phomopsis from blueberry and cranberry in the eastern United States. Mycologia 94:494-504.

12. Farr, D. F., and Rossman, A. Y. 2011. Systematic Mycology and Microbiology Laboratory Fungus-Host Database. Agricultural Research Service, United States Department of Agriculture, Beltsville, MD. http://nt.arsgrin.gov/fungaldatabases/fungushost/fungushost.cfm

13. Hewitt, W. B. 1951. Grape dead-arm control. Plant Dis. Rep. 35:142-143.

14. Kanematsu, S., Kobayashi, T., Kudo, A., and Ohtsu, Y. 1999. Conidial morphology, pathogenicity and culture characteristics of Phomopsis isolates from peach, Japanese pear and apple in Japan. Ann. Phytopathol. Soc. Jpn. 65:264-273.

15. Kanematsu, S., Minaka, N., Kobayashi, T., Kudo, A., and Ohtsu, Y. 2000. Molecular phylogenetic analysis of ribosomal DNA internal transcribed spacer regions and comparison of fertility in Phomopsis isolates from fruit trees. J. Gen. Plant Pathol. 66:191-201.

16. Larignon, P., and Dubos, B. 1997. Fungi associated with Esca disease in grapevine. Eur. J. Plant Pathol. 103:147-157.

17. Littell, R. C., Milliken, G. A., Stroup, W. W., Wolfinger, R. D., and Schabenberger, O. 2006. SAS for Mixed Models, second ed. SAS Institute Inc., Cary, NC.

18. Liu, D., Coloe, S., Baird, R., and Pederson, J. 2000. Rapid mini-preparation of fungal DNA for PCR. J. Clin. Microbiol. 38:471.

19. Michailides, T. J., and Morgan, D. P. 2004. Panicle and shoot blight of pistachio: a major threat to the California pistachio industry. APSnet Features. Online publication. doi:10.1094/APSnetFeature-2004-0104

20. Moller, W. J., and Kasimatis, A. N. 1978. Dieback of grapevines caused by Eutypa armeniacae. Plant Dis. Rep. 62:254-258.

21. Mostert, L., Crous, P. W., Kang, J.-C., and Phillips, A. J. L. 2001. Species of Phomopsis and a Libertella sp. occurring on grapevines with specific reference to South Africa: morphological, cultural, molecular and pathological characterization. Mycologia 93:146-167.

22. Nita, M., Ellis, M. A., and Madden, L. V. 2008. Variation in disease incidence of Phomopsis cane and leaf spot of grape in commercial vineyards in Ohio. Plant Dis. 92:1053-1061.

23. Nita, M., Ellis, M. A., Wilson, L. L., and Madden, L. V. 2006. Effects of application of fungicide during the dormant period on Phomopsis cane and leaf spot of grape disease intensity and inoculum production. Plant Dis.
90:1195-1200.

24. Nita, M., Ellis, M. A., Wilson, L. L., and Madden, L. V. 2006. Evaluation of a disease warning system for Phomopsis cane and leaf spot of grape: a field study. Plant Dis. 90:1239-1246.

25. Phillips, A. J. L. 1998. Botryosphaeria dothidea and other fungi associated with excoriose and dieback of grapevines in Portugal. J. Phytopathol. 146:327-332.

26. Phillips, A. J. L. 1999. The relationship between Diaporthe perjuncta and Phomopsis viticola on grapevines. Mycologia 91:1001-1007.

27. Pscheidt, J. W., and Pearson, R. C. 1989. Time of infection and control of Phomopsis fruit rot of grape. Plant Dis. 73:829-833.

28. Rambaut, A. 2002. Sequence Alignment Editor, version 2.0. Department of Zoology, University of Oxford, Oxford.

29. Rambaut, A. 2009. FigTree v1.3.1 2006-2009. Institute of Evolutionary Biology, University of Edinburgh, UK.

30. Ronquist, F., Teslenko, M., van der Mark, P., Ayres, D. L., Darling, A., Hohna, S., Larget, B., Liu, L., Suchard, M. A., and Huelsenbeck, J. P. 2012. MrBayes 3.2: efficient Bayesian phylogenetic inference and model choice across a large model space. Syst. Biol. 61:539-542.

31. Santos, J. M., Correia, V. G., and Phillips, A. J. L. 2010. Primers for matingtype diagnosis in Diaporthe and Phomopsis: their use in teleomorph induction in vitro and biological species definition. Fungal Biol. 114:255-270.

32. Schilder, A. M. C., Erincik, O., Castlebury, L., Rossman, A., and Ellis, M. A. 2005. Characterization of Phomopsis spp. infecting grapevines in the Great Lakes region of North America. Plant Dis. 89:755-762.

33. Sosnowski, M. R., Lardner, R., Wicks, T. J., and Scott, E. S. 2007. The influence of grapevine cultivar and isolate of Eutypa lata on wood and foliar symptoms. Plant Dis. 91:924-931.

34. Swofford, D. L. 2002. Phylogenetic Analysis Using Parsimony (*and other Methods), version 4. Sinauer Associates, Sunderland, MA.

35. Thomidis, T., and Michailides, T. J. 2009. Studies on Diaporthe eres as a new pathogen of peach trees in Greece. Plant Dis. 93:1293-1297.

36. Traverso, J. B. 1906. Flora Italica Cryptogama Pars 1, Fungi, fasc 1. Rocca S. Casciano, Firenze, Italy.

37. Tuset, J. J., and Portilla, M. T. 1989. Taxonomic status of Fusicoccum amygdali and Phomopsis amygdalina. Can. J. Bot. 67:1275-1280.

38. Udayanga, D., Liu, X., McKenzie, E. H. C., Chukeatirote, E., Bahkali, A. H. A., and Hyde, K. D. 2011. The genus Phomopsis: biology, applications, species concepts and names of common phytopathogens. Fungal Divers. 50:189-225.

39. Uecker, F. A. 1988. A world list of Phomopsis names with notes on nomenclature, morphology and biology. Mycol. Mem. No. 13. Cramer Publishers, Berlin.

40. Urbez-Torres, J. R., Adams, P., Kamas, J., and Gubler, W. D. 2009. Identification, incidence, and pathogenicity of fungal species associated with grapevine dieback in Texas. Am. J. Enol. Vitic. 60:497-507.

41. Urbez-Torres, J. R., Leavitt, G. M., Guerrero, J. C., Guevara, J., and Gubler, W. D. 2008. Identification and pathogenicity of Lasiodiplodia theobromae and Diplodia seriata, the causal agents of Bot Canker Disease of grapevines in Mexico. Plant Dis. 92:519-529.

42. Urbez-Torres, J. R., Leavitt, G. M., Voegel, T. M., and Gubler, W. D. 2006. Identification and distribution of Botryosphaeria spp. associated with grapevine cankers in California. Plant Dis. 90:1490-1503.

43. van Niekerk, J. M., Groenewald, J. Z., Farr, D. F., Fourie, P. H., Halleen, F., and Crous, P. W. 2005. Reassessment of Phomopsis species on grapevines. Australas. Plant Pathol. 34:27-39.

44. van Rensburg, J., Lamprecht, S., Groenewald, J., Castlebury, L., and Crous, P. 2006. Characterisation of Phomopsis spp. associated with die-back of rooibos (Aspalathus linearis) in South Africa. Stud. Mycol. 55:65-74.

45. Weber, E. A., Trouillas, F. P., and Gubler, W. D. 2007. Double pruning of grapevines: a cultural practice to reduce infections by Eutypa lata. Am. J. Enol. Vitic. 58:61-66.

46. White, T. J., Bruns, T., Lee, S., and Taylor, J. 1990. Amplification and direct sequencing of fungal and ribosomal RNA genes for phylogenetics. Pages 315-322 in: PCR Protocols: A Guide to Methods and Applications. Academic Press, Inc., San Diego, CA.

47. Willison, R. S., Chamberlain, G. C., Townshend, J. L., and de Ronde, J. H. 1965. Epidemiology and control of dead-arm of grapes. Can. J. Bot. 43:901-914.

48. Wingfield, M. J., De Beer, Z. W., Slippers, B., Wingfield, B. D., Groenewald, J. Z., Lombard, L., and Crous, P. W. 2012. One fungus, one name promotes progressive plant pathology. Mol. Plant Pathol. 13:604-613. 